\title{
Reflexão sobre a ação: experiências formativas de professores sobre a aprendizagem escolar
}

Reflection about the action: teacher's formative experiences on the topic of school learning

\author{
Dayanne Dailla da Silva Cajueiro ${ }^{1}$ \\ Eridete Arnaud de Pina ${ }^{2}$ \\ Terezinha Valim Oliver Gonçalves ${ }^{3}$
}

\section{Resumo}

Trata-se de uma pesquisa qualitativa na modalidade narrativa. Investigamos a experiência de dois professores sobre a reflexão sobre a ação docente. Objetivamos buscar aspectos que correspondem à reflexão metodológica, sobre o ensinar e sobre a aprendizagem escolar nessas narrativas. Neste sentindo, investigamos "Que aspectos procedimentais subjazem aos relatos de professores ao falarem sobre práticas docentes que visam a aprendizagem de seus alunos?". Para análise dos relatos, assumimos a análise textual discursiva (ATD). Da imersão nos textos de campo, emerge dois eixos de análise: i) A afetividade como princípio pedagógico; II) Reconstruindo abordagens de ensino por meio de reflexões. Concluímos que os sujeitos percebem fatores essenciais que contribuem para o ensino de qualidade, enfatizando a afetividade como fator primordial em todo o processo no que diz respeito à relação professor-aluno-conhecimento.

Palavras chave: reflexão; docência; pesquisa narrativa; afetividade.

\section{Abstract}

It's a qualitative research on the narrative modality. We investigated two teachers' experiences about reflection on teachers action. We looked forward to search for aspects that correspond to the methodological reflection, about school teaching and learning, on these narratives. Following this, we investigated "Which procedural aspects lay under teacher's stories when talking about teaching practices on the topic of student learning?". For the analisys of the stories, we utilized discursive textual analisys (DTA). From the imersion on field texts, emerges two analisys axes: i) The afetivity as a pedagogical principle; ii) Recontructing teaching approaches through reflections. We concluded that the subjects notice essential factors that contribute to quality teaching, emphasizing the afetivity as a primary factor throughout all the process, on the topic of relationship among teachers, students and knowledge.

Keywords: reflection; teaching; narrative reasearch, afetivity. 


\section{Ideias iniciais: investigando a experiência}

Consideramos o falar de si, o relato de experiências vividas como um dos caminhos principais para o processo de reflexão sobre as práticas docentes, uma vez que, segundo Larrosa (2014, p. 18), a experiência é "o que nos passa, o que nos acontece, o que nos toca. Não o que se passa, não o que acontece, ou o que toca". Nesse sentido, a experiência não é ignorada, ela toca nosso subjetivo em um processo de reconfiguração contínua. Ao vivenciar experiências, nosso ser é implicado, provocando-nos ressignificações que nos fazem refletir sobre "ser o que é".

Nessa direção, Dewey considera que a experiência precisa da reflexão sobre o que se viveu e que reviver uma experiência é apenas uma reprodução dimensional. Ele acredita que para a melhoria da educação se deve estudar a experiência de vida de professores, pois este processo iria possibilitar uma melhor compreensão do "caminhar" e dos segmentos da educação, estando o social e o pessoal, presentes. Para ele, o contínuo é critério para a experiência (MACEDO, 2015).

Oliveira; Alves, (2001) e Ferraço (2003) corroboram com tais ideias, ao afirmarem que ao pesquisar a experiência, o pesquisador mergulha no cotidiano daqueles que as vivenciam e isto irá implicar no universo pesquisado. Este fato irá torná-lo parceiro e não observador dos "outros". Este tipo de pesquisa se constitui em um processo investigativo acerca do/com "os saberes da experiência resultam do vivido pensado" (MACEDO, 2015, p. 19). $O$ autor ainda diz que

Acrescente-se, que a compreensão da experiência só se fará por atos de compartilhamento de sentidos e significados, tendo como fonte fulcral a vivência singular dos sujeitos na sua emergência existencial e sociocultural, a experiência se estrutura como um denso e complexo processo de subjetivação de tudo que nos acontece, que nos passa, mediado por desejos, escolhas e intenções conscientes ou não, lúcidas ou erráticas, plasmados num certo tempo mas, também, tocada intensamente pela impermanência (MACEDO, 2015, p. 19 grifo do autor).

À luz do pensamento narrativo, de Clandinin e Connelly (2011), entendemos que a experiência está presente continuamente no sujeito, é inseparável do sujeito e do contexto e se desenvolve a partir de outras experiências e, assim, em um continuum sucessivo. Não importa onde a pessoa se "posicione nesse continuum - o imaginado agora, algo imaginado no passado, ou um imaginado no futuro - cada ponto tem uma experiência passada como base e cada ponto leva a uma experiência futura" (CLANDININ; CONNELLY, 2011, p. 30). Nessa perspectiva, os autores ressaltam que a narrativa é a melhor maneira de representar e entender a experiência, como corrobora Souza (2004, p. 15), ao dizer:

[...] as narrativas de formação têm sido utilizadas como procedimento de recolha das fontes e, também, como potencializadora de um trabalho formativo, porque possibilitam a organização das experiências vividas através da preparação que 0 autor faz para o seu relato [...], configurando-se também como uma prática reflexiva das experiências, através de autoanálise empreendida enquanto dispositivo de investigação e formação. 
Sendo assim, alguns autores (FREIRE 1996; GONÇALVES, 2000; 2016; PERRENOUD 2002; SOUZA, 2006; ROCHA \& REIS, 2020; BARBISAN \& MEGID, 2018) vem defendendo 0 uso da abordagem narrativa, tanto como estratégia de pesquisa educacional, quanto como estímulo e estratégia de desenvolvimento profissional de professores. Esta abordagem de pesquisa qualitativa tem como objeto investigativo as experiências dos sujeitos, suas representações sobre a identidade profissional, os ciclos de vida, a fim de entender os sentidos e as situações vivenciadas no contexto escolar (SOUZA, 2006), social ou de formação inicial e continuada, dentre outros possíveis. Deste modo, concordamos que

a história oral é um procedimento metodológico que busca, pela construção de fontes e documentos, registrar, através de narrativas induzidas e estimuladas, testemunhos, versões e interpretações sobre a História em suas múltiplas dimensões: factuais, temporais, espaciais, conflituosas, consensuais. Não é, portanto, um compartimento da história vivida, mas sim, o registro de depoimentos sobre essa história vivida (DELGADO, 2006, p.16)

Ao ouvir relatos de professores sobre o percurso formativo, compreendemos que a experiência formativa é aquela que produziu reflexões marcantes e influíram sobre a prática de docência, ou seja, aquela a partir da qual o professor tomou decisões e ressignificou sua prática. Segundo Gonçalves (2000, p.104) "quando os professores vivenciam situações profissionais desafiadoras elas se tornam formativas, contribuindo para o desenvolvimento diferencial do sujeito como processo reflexivo, singular e autônomo". Tais contribuições, citadas pela autora, dizem respeito a ações que incentivam a realização de pesquisas que visem identificar como esses professores dão sentido às experiências vivenciadas no processo de formação inicial/continuada.

Nesta perspectiva, Perrenoud (2002) afirma que a reflexão intencional, regular e metódica conduz à tomada de consciência e possíveis mudanças na prática. Portanto, a produção escrita sobre essas vivências é uma forma de o sujeito fazer contato com elas (tomar consciência), podendo assim desencadear um processo de constituição de identidade profissional. Podemos tomar como exemplo o uso do diário de bordo, por ser uma estratégia que favorece o processo reflexivo. Ele se configura como um espaço onde o sujeito registra os acontecimentos vividos, sua percepção sobre eles, e este também pode representar um instrumento de pesquisa, uma vez que, de acordo com Freire (1996, p. 6) "quando escrevemos, desenvolvemos nossa capacidade reflexiva sobre o que sabemos e o que ainda não dominamos". Essa produção é um processo de autoconhecimento que pode ser usado para firmar escolhas e trabalhar com as possíveis dificuldades e lacunas desses sujeitos. Segundo Reis (2008, p. 3):

Os professores, quando contam histórias sobre algum acontecimento do seu percurso profissional, fazem algo mais do que registrar esse acontecimento; acabam por alterar formas de pensar e de agir, sentir motivação para modificar as suas práticas e manter uma atitude crítica e reflexiva sobre o seu desempenho profissional.

Essa troca de saberes e experiências, por meio de narrativas de si, permitem que se faça uma análise das experiências ao largo de suas vidas e como estas implicam em suas escolhas, opções metodológicas e na própria prática docente. Nesse sentido, concordamos 
com Nóvoa (1995, p.25), ao afirmar que "estar em formação implica um investimento pessoal, livre e criativo sobre os percursos e os projetos próprios, com vistas à construção de uma identidade pessoal, que é também uma identidade profissional".

É neste sentido que temos a intenção de compreender que tipos de saberes surgem nas histórias de vida de dois professores, e como as experiências vividas e relatadas podem contribuir para construção de práticas docentes com vistas a impulsionar a aprendizagem de seus alunos. Portanto, nesta perspectiva de reflexão sobre a ação, em busca de novos modelos de ensino e metodologias, é que surge a nossa pergunta de pesquisa: Que aspectos procedimentais subjazem aos relatos de professores ao falarem sobre práticas docentes que visam à aprendizagem de seus alunos?

\section{Os caminhos investigativos da narrativa}

As experiências que constituem textos de campo desta pesquisa, juntamente com as entrevistas semiestruturadas, foram vivenciadas por dois professores que estavam em formação continuada e que passaram por um processo de reflexão ao contarem suas histórias de vida pessoal e profissional, sendo uma professora formada em Pedagogia, em processo de mestrado, chamada ficticiamente de Rita e um professor formado em Letras, em processo de doutoramento, chamado, também ficticiamente, de Wando. Em contexto investigativo, ambos foram solicitados a escrever cada qual uma carta para um aluno fictício, na qual deveriam expressar o que consideram importante ao ensinar. Realizamos também uma entrevista semiestruturada, que foi transcrita para a análise. Constituíram-se textos de campo, portanto, as cartas e a transcrição das entrevistas realizadas.

Por essa característica experiencial dos relatos docentes sobre a docência praticada, optamos pela pesquisa narrativa, uma vez que "[...] não há o sentimento de expectativa somente pelo que está por vir, mas também por toda a história que lá já existe". (CLANDININ e CONNELLY, 2011, p.107). Pois assim, entendemos que em processos formativos de sujeitos, este tipo de pesquisa nos ajuda a refletir a respeito da contextualização do passado em torno do presente, "no devir de como a nossa vida sofre interferências das instituições pelas quais passamos, em especial, no que trata sobre o que aprendemos e o que ensinamos" (LIMA, 2015, p. 20). Em outras palavras:

A narrativa tornou-se um caminho para o entendimento da experiência. Nossa excitação e interesse pela narrativa tem sua origem e interesse na experiência. Tendo a narrativa como nossa posição estratégica, temos um ponto de referência, a vida e um chão, uma base de suporte ou para imaginarmos o que a experiência é e para imaginar como ela pode ser estudada e representada em textos de pesquisa (CLANDININ e CONNELLY, 2011, p.27).

Por isso, utilizamos os relatos como recortes metodológicos, para possíveis reflexões sobre a experiência individual de vida, relacionando-as a experiências coletivas como constructos históricos sociais, uma vez que "a memória atualiza o tempo passado, tornando-o tempo vívido e pleno de significados no presente" (DELGADO, 2006, p. 38).

Para análise dos textos de campo, adotamos a Análise Textual Discursiva (ATD) (MORAES; GALIAZZI, 2007, 2016). A ATD se baseia na interpretação e construção de novos entendimentos sobre as narrativas investigadas que constituem os textos de campo 
(MORAES; GALIAZZI, 2007, 2016), ou seja, levantamos as entrevistas e as cartas escritas pelos sujeitos investigados (as narrativas) que fizeram a composição do texto de campo, posteriormente demos sentidos que percorrem nosso foco investigativo. O procedimento da análise resultou na organização desse material empírico em dois eixos temáticos: i) A afetividade como princípio e ii) Reconstruindo metodologias de ensino por meio de reflexões.

Antes de analisarmos os eixos supracitados iremos dar a conhecer os sujeitos investigados por meio de suas narrativas, uma vez que entendemos que quando nossas histórias e memórias são resgatadas à medida que as narramos, passamos a refletir sobre o processo que nos fez ser o que somos. Parafraseamos Benjamin (1980, p. 60), quando diz que "o narrador colhe o que narra na experiência própria ou relatada e transforma isso outra vez em experiência dos que ouvem sua história", uma vez que, ao mergulharmos em nossas memórias passamos a perceber escolhas que nos motivaram a ter atitudes que nos movem no presente. É neste sentido que narrar nos possibilita "questionamento de posturas a partir das ações; percepção do que domina e consciência do que precisa saber/aprender; o desejo de mudança; o estabelecimento de responsabilidades e metas a atingir" (REIS, 2008, p.4), como nos mostram Wando e Rita.

\section{Conhecendo os Sujeitos por meio de suas narrativas}

O professor Wando relata experiências de uma fase de sua carreira docente, quando ministrava aulas na Academia das Agulhas Negras vindo a trabalhar, posteriormente, na graduação do curso de Letras, onde ocorreu sua última atuação, antes de se afastar para o doutorado. Como professor de pós-graduação lato sensu naquele espaço, lembra que, desde 2004, trabalha com adulto, embora sejam públicos totalmente diferentes a cada nova experiência. A professora Rita, por sua vez, narra sua experiência atual com crianças de cinco a sete anos de idade, enfatizando os desafios enfrentados no seu cotidiano pessoal ou de sua prática docente, destacando como as conquistas de seus alunos influenciam em sua postura profissional.

Os professores Wando e Rita consideram suas experiências em sala de aula como fundamentais na construção de suas identidades profissionais e aprendizagem de seus alunos. Wando diz em sua narrativa que "o sucesso ou insucesso de certas experiências 'marcam' nossa postura pedagógica" (Entrevista de Wando, 2018). Nessa mesma linha de reflexão sobre sua prática, a professora Rita também manifesta preocupação com as experiências vividas no percurso de sua carreira: "eu estou nesse processo de construção e reconstrução e o meu foco e o meu olhar é para aprendizagem dos meus alunos." (Entrevista de Rita, 2018). Somente o sujeito da experiência está, portanto, aberto à experiência da transformação, pois é nesse movimento de ir e vir, de construir e reconstruir a partir da reflexão de experiências vividas que nossos sujeitos vão construindo suas práticas como professores, uma vez que, a exemplo do que diz Freire (1996, p. 29) "enquanto ensino continuo buscando, (re)procurando" e aprendendo. 


\title{
Resultados e discussões: narrativa de quem ensina e se faz docente
}

Nesta seção, buscamos responder ao objetivo a que nos propomos nesta pesquisa ao analisar as narrativas dos professores Wando e Rita nos referidos eixos de análise supracitados como seguem.

\section{A afetividade como um princípio}

A sala de aula é um espaço cheio de vida, é dinâmico, está recheado de emoções e sentimentos, pois nela convivem diariamente pessoas com diferentes experiências, valores e motivações. A comunicação e o diálogo tornam-se a principal via para estabelecer relações, pois é nesse espaço que o processo ensino-aprendizagem se desenvolve. É nesse ambiente que são construídas as relações professor-alunoconhecimento, com base no diálogo, na afetividade, na cumplicidade. Nesse sentido, apoiadas em Freire, podemos dizer que faz parte da prática do professor o querer bem aos seus alunos. Nas palavras do autor:

\begin{abstract}
Esta abertura de querer bem não significa, na verdade, que, porque professor, me obrigo a querer bem todos os alunos de maneira igual. Significa, de fato, que a afetividade não me assusta, que não tenho medo de expressá-la. Significa esta abertura ao querer bem a maneira que tenho de autenticamente selar o meu compromisso com os educandos, numa prática específica do ser humano (FREIRE, 2007, p. 141).
\end{abstract}

Desde o início do século XX os professores vêm considerando a afetividade como uma das dimensões mais importantes no processo de ensino-aprendizagem, "pois sua presença na educação potencializa e impulsiona o processo educativo de tal forma que o educando se sente mais motivado pela aprendizagem que lhe é proposta" (COUTINHO, p.1, 2018).

A professora Rita evidencia a importância que atribui à afetividade em aula quando expõe sua preocupação em conhecer seus alunos, considerando as dificuldades encontradas na infância, no que diz respeito à relação entre os pares, à própria relação entre o ensino e aprendizagem, aspectos que se fazem presentes quando ela assume a responsabilidade pela não aprendizagem do conteúdo por parte dos alunos. Isto fica evidente na sua narrativa, quando diz: "Quero segurar a sua mão..."; "estou aqui para te tranquilizar..."; "Quero segurar sua mão e superar todas as dificuldades" (entrevista de Rita, 2018). Ela enfatiza isso ao ser entrevistada: "Eu conheço, eu procuro conhecer muito o meu aluno, muito a minha criança porque eu digo para eles: "eu vou passar um ano com você, então eu quero te conhecer" (entrevista de Rita, 2018). Tardif e Lessard (2007) nos dizem que é na relação com o seu aluno que o professor percebe o quanto é desafiador o seu trabalho, devido à influência preponderante dos afetos e emoções que são vivenciadas a todo tempo, ora prazerosas, ora decepcionantes.

Rita destaca a necessidade de uma aproximação familiar, ou seja, busca manter um diálogo diário com os pais de seus alunos procurando conciliar o processo de ensino aprendizagem com as vivências deles. Em suas palavras: 
Eles vão evoluindo e eu percebo, claramente, no primeiro ano essa evolução. E essa evolução, eu atribuo não só ao meu [trabalho], mas ao trabalho em parceria com as famílias, com os pais. [...]eu acredito que para atingir essa aprendizagem, nós precisamos ter um desdobramento, nós precisamos, "atacar" de várias e várias formas: é no diálogo com as famílias, no diálogo com a coordenação... Eu tenho um apoio muito grande da coordenação da escola e a própria experiência, talvez por eu ser apaixonada pelo primeiro ano. Eu já trabalho com o primeiro ano há três anos com turma de primeiro ano, porque eu fico fascinada com o resultado (entrevista de Rita, 2018).

As salas de aulas são carregadas de interações e experiências. Cabe ao professor a gerência dessas relações, pois cada um possui saberes que os constituem como sujeitos de sua própria história. Ao cultivar os vínculos, o professor direciona o processo de aprendizagem dos alunos. Tardif e Lessard (2007) nos lembram de que o trabalho do professor é essencialmente interativo. Do ponto de vista da ação comunicacional, "ensinar não é, tanto, fazer alguma coisa, mas fazer com alguém alguma coisa significativa" (TARDIF; LESSARD, 2007, p. 249).

Conforme Maturana (1993), uma das tarefas do professor é de criar um ambiente de "convivência ao qual se convida o outro, de modo que o outro esteja disposto a conviver conosco, por um certo tempo, espontaneamente" (p. 32).

O professor Wando também traz em suas falas a afetividade como um fator essencial à aprendizagem dos alunos. Wando diz: "normalmente, quando consigo tecer essa empatia com o aluno, e ele consegue ser meu amigo, ele realmente aprende" (Wando, novembro/2018). Para o professor, todo processo que se inicia na sala de aula tem a ver com a "empatia", com o colocar-se no lugar do aluno. Isto ocorreu em sua experiência na Academia das Agulhas Negras, nos cursos de graduação e de pós-graduação em que atuou. Wando se diz "muito tecnológico", gosta de utilizar os recursos disponíveis das redes sociais para se aproximar mais de seus alunos, tudo para garantir o que ele chama de uma "boa relação empática e afetiva", como fonte de sucesso da aprendizagem na disciplina que ministra. Lembramos Tardif e Lessard, ao discutirmos o envolvimento do professor com o aluno no processo ensino aprendizagem. Assim dizem os autores:

Quando se ensina, não se pode deixar sua personalidade no vestuário, nem o espírito no escritório, nem sua afetividade em casa. Pelo contrário, esses fenômenos são elementos intrínsecos ao processo do trabalho (TARDIF; LESSARD, 2007, p. 267, 268).

Concordando com os autores, entendemos, com Freire (1996, p 33) que "o bom professor é o que consegue, enquanto fala, trazer o aluno até a intimidade do movimento do seu pensamento. Sua aula é, assim, um desafio e não uma cantiga de ninar. Seus alunos cansam, não dormem, cansam porque acompanham as idas e vindas de seu pensamento, surpreendem suas pausas, suas dúvidas, suas incertezas". Ou seja, a aula está impregnada de afetividade que se deseja sempre positiva para, de fato, impulsionar a aprendizagem do aluno e a (trans)formação do professor. 


\section{Reconstruindo metodologias de ensino por meio de reflexões}

De acordo com Schön (1992, p. 62), "as práticas reflexivas envolvem conceitos distintos que mobilizam a reflexão na ação, a reflexão sobre a ação e a reflexão sobre a reflexão na ação". São práticas inovadoras e não constituem tarefa fácil, pois exigem um movimento constante de ir da reflexão para a ação e da ação para a reflexão, como um caminho para a construção do ensino e da aprendizagem. Nesse contexto de pensar e repensar, no agir e reagir, do planejar e replanejar, encontramos os professores Wando e Rita imersos no processo.

Esse aspecto aparece em trechos da entrevista de Wando quando ele narra: "na sala de aula da graduação estou o tempo todo em construção da formação, nesse ir e vir, nas disciplinas linguísticas, quando avanço e percebo que isso eles não sabem, então preciso replanejar, o que foi planejado nem sempre dá para fazer" (Entrevista de Wando, 2018).

Wando mostra um constante exercício de reflexão na ação no processo de aprendizagem dos alunos, da mesma maneira que expressa na narrativa que "é necessário que saibamos qual o momento de refazermos os planejamentos" (Entrevista de Wando, 2018). Ele lembra, durante a entrevista, de sua experiência com a Pesquisa Narrativa numa disciplina do curso de doutorado, que não conhecia e que acaba percebendo que ela está presente em sua prática docente, pois na sala de aula da graduação está o tempo todo em construção da formação. Nesse ir e vir, nas disciplinas de natureza linguística, quando avança e percebe que eles não sabem algo, propõe-se a replanejar, reconhecendo que o que foi planejado nem sempre dá para fazer. Ele faz uma ementa que pode não ser seguida totalmente. Esse talvez seja o ir e vir, um ir e vir positivo que professores realmente precisam vivenciar na sua especialização, na sua formação. Assim, "a prática docente crítica, implicante do pensar certo, envolve o movimento dinâmico, dialético, entre o fazer e o pensar sobre o fazer" (Freire, p. 38).

Processo similar ocorre com a professora Rita. Ao refletir sobre suas práticas, a professora percebe que precisa reconstruir seus métodos, quando visualiza que seus alunos demandam estímulos diferentes por estar em contextos diferentes. Isto fica claro para ela, ao analisar alguns testes que foram feitos com eles durante o bimestre. Ela percebe que uma minoria de crianças não estava acompanhando os demais e visualizou o que poderia estar impedindo este progresso. Ela reflete, nos seguintes termos:

Esses testes mostram, claramente, a progressão da criança e aquela criança que vai ficando para trás em relação à maioria da turma é aquela criança que fica para trás que é meu foco, é nela que vou concentrar a maior parte do meu tempo, é com ela que eu vou dialogar mais. Eu sempre vou trazer material extra para ela e vou tentar envolver ainda mais a família. As crianças geralmente que tem mais dificuldade são crianças cujas famílias são desestruturadas, então a culpa não é da família, mas é do contexto, mas eu procuro saber, procuro compreender como é que a criança vive. Elas chegam e fazem o relato, eu compreendo a realidade e eu tenho que buscar outras alternativas para lidar com aquela criança". (entrevista de Rita, 2018).

Rita manifesta ser reflexiva em sua prática docente e, ao relatá-la, certamente, revive a experiência e continua sua formação profissional, reconstituindo-se. Bueno (2002, p.23) afirma que "ao voltar-se para seu passado e reconstituir seu percurso de vida, o indivíduo 
exercita sua reflexão e é levado a uma tomada de consciência, tanto no plano individual, como no coletivo".

Podemos perceber a sensibilidade da professora com aquele que precisa mais de sua atenção. Eis que surge o processo de ressignificação do ensino, uma vez que ela se responsabiliza pela aprendizagem desse aluno, buscando, portanto, outras maneiras de ensinar. Neste sentido, Rita se manifesta, nos seguintes termos:

no planejamento eu fico bem ansiosa, mesmo, para eu tentar atingir a todos, cada um da sua forma, mas procuro atingir a todos eles. O ideal seria que todos caminhassem juntos, mas não existe isso [...]. No geral, eu trabalho nessa perspectiva de formar neles tanto atitude de autonomia para que eles zelem pelas coisinhas deles, pelos livros deles. Eu faço toda segunda-feira, dou um tempinho para eles irem para a biblioteca e escolher o livro e levar para casa. São pequenas práticas que se você já introduziu no primeiro ano vai ser natural (entrevista de Rita, 2018).

Rita não dá a conhecer sobre a origem desse modo de ser e estar na docência, ao evidenciar o que tanto é desejável na profissão: o compromisso com o outro, com a formação de bons hábitos que contribuam para a formação do cidadão. É possível, mas muito difícil situar experiências formativas que nos constituem professores. Contudo, elas podem se situar em período anterior à formação profissional. GONÇALVES, 2000 diz que:

[...] Muitas de suas ideias, atitudes e comportamentos sobre o ensino, ou a forma que ensinam, são devidos à longa formação ambiental, durante o período em que foram alunos. A influência dessa formação ambiental é enorme porque corresponde a experiências reiteradas relativas ao ensino, à aprendizagem, à avaliação, à relação professor-aluno, ao papel do professor e do aluno em aula (p. 156).

Ainda nesta direção a professora, em sua narrativa, diz que, ao se deparar com vários episódios de frustração, ao perceber que seus alunos não estavam aprendendo ou que em alguns momentos não conseguiu corresponder às expectativas de seus alunos em situações em que eles perguntavam e ela não sabia responder à curiosidade, decidiu que deveria retornar à universidade em busca de uma formação continuada para que pudesse corresponder às demandas do alunado deste século, visto que eles estão envolvidos em várias atividades e conhecimentos que são disponibilizadas com mais facilidade, como fica expresso a seguir:

Eu acho que o que motiva essa busca pela formação, uma formação mais ampla, uma formação, de fato, em um centro de conhecimento como a universidade, onde eu acredito que todos os professores deveriam ter a oportunidade de continuar, de fato, a sua formação e avançar e levar novas leituras, foi que depois de eu vir para cá para fazer o mestrado, eu tive leituras de teóricos que eu não conhecia, que muitos deles trazem a reflexão na nossa ação, a reflexão do nosso dia a dia, da reflexão da prática, do ideal do professor pesquisador que é o professor que se põe a refletir, realmente, sobre a sua realidade, sobre a sua prática, sobre o que ocorre, como ocorre... Então, isso é um referencial teórico que, para mim, é novo, é novidade. Então, eu já mudei muito desde quando eu voltei 
para a academia, voltei para o mestrado. Eu já mudei muito na minha prática e eu estou assim nesse processo de construção e reconstrução e o meu foco e o meu olhar é para a aprendizagem dos meus alunos" (Entrevista de Rita, 2018).

Partindo da experiência do que fazemos, do que dá certo ou não, do parar para pensar sobre o que fazemos, ou, ainda, do pensar enquanto fazemos sobre o que estamos fazendo, estamos partindo do que Schön (1992) chama de reflexão na ação sobre a ação. Essa prática de reflexão nos permite experimentar situações, ao mesmo tempo em que se experimentamos compreensões que permitem realizar transformações em situações necessárias. Tais reflexões só são possíveis quando amparadas por referenciais teóricos consistentes.

\section{Considerações finais}

Ao retornarmos às nossas memórias, refletimos sobre o vivido, produzindo autoconhecimento, (trans)formação e conhecimento profissional. Foi exatamente nesse processo de reflexão sobre a própria prática, apoiados por referenciais teóricos de seus respectivos cursos de pós-graduação, que encontramos os sujeitos de nossa pesquisa.

Rita e Wando, ao analisarem suas relações com seus alunos, refletem sobre a maneira de dar aula e desenvolver metodologias de ensino-aprendizagem. Neste processo, surge em seus relatos uma similaridade entre ambos sobre a defesa da presença da relação afetiva positiva entre professor-aluno no ensino, cada um a seu jeito e modo de fazer, tendo como consequência uma relação afetiva positiva na tríade professor-aluno conhecimento.

Wando defende que a aprendizagem de seus alunos está intimamente ligada à conexão afetiva e de identificação entre professor e aluno. Ele compreende que este processo, ao mesmo tempo em que contempla o conteúdo que vai ensinar, possibilita, por meio de suas experiências docentes, uma espécie de autoformação, visto que estará aprendendo simultaneamente com seus próprios alunos.

Rita vai além em suas ações e reflexões, ao associar a aprendizagem de seus alunos a métodos que utiliza e que envolvem a ação coletiva entre ela, a família e o serviço de coordenação escolar para que seus alunos progridam nos conteúdos que ensina. Ela reconhece que as atividades extras que providencia aos alunos com alguma dificuldade de aprendizagem são importantes para os alunos que apresentam dificuldades de aprendizagem e, ao perceber esta vertente, vai à busca de formação continuada, em nível de pós-graduação, vislumbrando melhorias para a educação de seus alunos e seu modo de pensar sobre a docência.

É possível perceber que ressignificar a experiência é ver novas maneiras de formação e ensino em um processo de ir e vir do passado para o presente, vislumbrando planos e objetivos para o futuro e isso se chama reflexão, constituindo-se um processo em que se observam e avaliam fatos e tomam-se decisões para alterações do status quo. A reflexão sobre a ação docente se evidencia ao produzirmos uma descrição verbal sobre fatos ou situações vividas, expressar inquietações por estas provocadas e manifestar construção de encaminhamentos e tomadas de decisão para a solução do problema, avaliando o processo 
vivido, isto é, fazendo uma reflexão sobre nossa reflexão da ação passada, o que foi evidenciado por ambos os professores colaboradores da pesquisa.

É neste sentindo que acreditamos que o professor possa descobrir em si as suas próprias potencialidades, assim como buscar em seu passado aquilo que o constitui e, a partir disto, construir o seu presente e o seu futuro, pois assim ele será capaz de interpretar outras experiências, de se inspirar nelas, de criar, recriar e de transformar as suas próprias, visando novas perspectivas para a sua prática docente e para a educação deste século recém iniciado.

\section{Referências}

ALMEIDA, P. C. A; BIAJONE, J. Saberes docentes e formação inicial de professores: implicações e desafios para as propostas de formação. Educação e Pesquisa, São Paulo, v.33, n.2, p. 281-295, maio/ago, 2007.

BARBISAN, C.; MEGID, M. A. B. A. Categorias de narrativas: principais usos em pesquisas e formação de pedagogas. ETD - Educação Temática Digital, Campinas, SP, v. 20, n. 4, p. 979-996, 2018. DOI: 10.20396/etd.v20i4.8649944.

BENJAMIN, W. O Narrador. São Paulo: Abril Cultural - Coleção Os Pensadores,1980.

BUENO, B. O. O método autobiográfico e os estudos com histórias de vida de professores: a questão da subjetividade. Revista Educação e Pesquisa, v. 28, n¹, 2002.

CATANI, Denice Barbara et al. História, memória e autobiografia na pesquisaeducacional e na formação. In: CATANI, Denice Barbara et al (Orgs). Docência, memória e gênero: estudossobreformação. São Paulo: EscriturasEditora, 2003.

CLANDININ, D. Jean; CONNELLY, F. Michael. Pesquisa narrativa: experiência e história em pesquisa qualitativa. Trad. Grupo de Pesquisa Narrativa e Educação de Professores ILEEI/UFU. Uberlândia: EDUFU, 2011. 250 p.

DELGADO, L. de A. N.. Historia Oral: memória, tempo, identidades. Belo Horizonte: Autentica, 2006.

FERRAÇO, C. E. Eu, caçador de mim. In: GARCIA, R.L. (Org). Método: Pesquisa com o cotidiano. Rio de Janeiro: DP\&A, 2003.

FREIRE, Madalena. Observação, registro e reflexão: instrumentos metodológicos 1, SP: Espaço Pedagógico, 1996.

FREIRE, Paulo. Pedagogia da autonomia: saberes necessários à prática educativa. São Paulo: Paz e Terra, 1996.

FREIRE, Paulo. Pedagogia da Autonomia: saberes necessários à prática educativa. São Paulo: Paz e Terra, 2007.

GONÇALVES, Terezinha Valim Oliver. Ensino de Ciências e Matemática e Formação de Professores: marcas da diferença. 2000. Tese (Doutorado) - Doutorado em Educação. Universidade Estadual de Campinas.

GONÇALVES, Terezinha Valim Oliver. Aspectos epistemológicos da Pesquisa Narrativa presentes em teses e dissertações sobre formação de professores na área de Educação em 
Ciências e Matemáticas, no período de 2000 a 2012. In: Congresso Iberoaamericano de Investigação Qualitativa - CIAIQ 2016, 2016, PORTO - Pt. Atas - Investigação Qualitativa em Educação. v. 1. p. 1065-1074, PORTO/PT: Ludomedia, 2016.

JOSSO, Marie-Christine. Experiências de Vida e Formação. São Paulo: Cortez, 2004.

MACEDO, R.S. Pesquisar a experiência compreender/mediar saberes experienciais. -1 Educação - Curitiba, PR: CRV, 2015.

NÓVOA, A. Formação de professores e profissão docente. In: NÓVOA, A. (Org.). Os professores e sua formação. 2a ed. Lisboa: Dom Quixote. 1995. p. 15-34.

OLIVEIRA, I. B.; ALVEZ,N. A pesquisa no/do cotidiano das escolas: sobre redes e saberes, Rio de Janeiro: DP\&A, 2001.

PERRENOUD, Philippe. A prática reflexiva no ofício de professor: profissionalização e razão pedagógica. Porto Alegre: Artmed Editora, 2002.

REIS, P. As Narrativas na formação de professores e na investigação em educação. Nuances: estudos sobre Educação. Presidente Prudente, SP, ano XIV, v. 15, n. 16, p. 17-34, jan./de 2008

SOUZA, E.C.de (Org.). Autobiografias, História de Vida e Formação: pesquisa e ensino. Salvador/Bahia: EDUNEB - EDIPUCRS, 2006.

SCHÖN, Donald. La formacion de profissionales reflexivos. Barcelona: Paidós, 1992.

LARROSA, Jorge. Tremores: escritos sobre experiência. Belo Horizonte: Autêntica, 2014.

LIMA, D.D.R.S. Clube de Ciências da UFPA e Docência: experiências formativas desde a infância. Tese (doutorado) 2015. Doutorado em Educação em Ciências. Universidade Federal do Pará.

MATURANA, Humberto. As bases biológicas do aprendizado. Dois Pontos, v. 2, n.16, 1993.

MORAES, R; GALIAZZI, M. C. Análise textual discursiva. ljuí: Unijuí, 2007.

MATURANA, Humberto. Análise textual discursiva. ljuí: Unijuí, 2016. 264p.

ROCHA, L. P.; REIS, M. B. de F. A pesquisa narrativa em educação especial. Revista IberoAmericana de Estudos em Educação, Araraquara, v. 15, n. esp.1, p. 884-899, 2020. DOI: 10.21723/riaee.v15iesp.1.13500.

TARDIF, Maurice; LESSARD, Claude. O trabalho docente: elementos para uma teoria da docência como profissão de interações humanas. Trad. João Batista Kreuch. $13^{a}$ edição. Petrópolis: Vozes, 2007. 